\title{
USGS Microbiome Research
}

Microbiomes are the communities of microorganisms (for example, bacteria, viruses, and fungi) that live on, in, and around people, plants, animals, soil, water, and the atmosphere. Microbiomes are active in the functioning of diverse ecosystems, for instance, by influencing water quality, nutrient acquisition and stress tolerance in plants, and stability of soil and aquatic environments. When new environmental conditions cause the composition of a microbiome to change, such that some microorganisms become pathogenic (capable of causing disease) or overgrowth occurs among certain microbial groups, altering the function of the microbiome, these dysfunctional microbiomes can cause visible problems. Results of dysfunctional microbiomes include coral disease, reduced agricultural crop production, and contaminated waterways. Microbiome research will fundamentally strengthen the ability to address the global challenges of maintaining clean water, ensuring adequate food supply, meeting energy needs, and preserving human and ecosystem health.

The National Microbiome Initiative was announced by the White House Office of Science and Technology Policy in 2016, in collaboration with Federal agencies and private-sector stakeholders, with the 5-year goal of promoting the integrated study of microbiomes across different ecosystems. The initiative aims to advance the understanding of microbiome behavior and enable protection and restoration of healthy microbiome function. This call to action echoes the on-going goals of microbiome research within the U.S. Geological Survey (USGS) science mission and highlights an area of study that USGS scientists have been engaged in for more than a decade.
The U.S. Department of Interior (DOI) protects and manages the Nation's natural resources and cultural heritage, and provides scientific and other information about those resources. The USGS is the sole science agency for the DOI and conducts studies on the natural hazards that threaten lives and livelihoods; water, energy, minerals, and other natural resources we rely on; the health of our ecosystems and environment; and the impacts of climate and land-use change. Because of this broad mission, there is no single microbiome program within USGS; rather, microbiome research is embedded within the many mission areas. Key research areas include water quality (assessing microbiomes of water resources such as groundwater, streams, springs, and lakes; investigating environmental microbiomes associated with harmful algal blooms); understanding climate effects on soil and permafrost microbiomes; ecosystem health (determining the microbiomes of marine ecosystems, including tropical coral reefs, deep-sea coral habitats, and seeps); wildlife health; characterizing invasive species microbiomes; monitoring microbiomes of contaminated environments, such as acid mine drainage, uranium mines, and landfills to improve bioremediation; and stimulating microbiomes of energy and mineral resources to enhance production (fig. 1). USGS research supports the needs of other Federal agencies, including the U.S. Environmental Protection Agency, U.S. Fish and Wildlife Service, National Park Service, Bureau of Ocean Energy Management, National Oceanic and Atmospheric Administration, National Aeronautics and Space Administration (NASA), and the U.S. Department of Energy, as well as numerous local, state, and Tribal agencies.

\section{Permafrost}

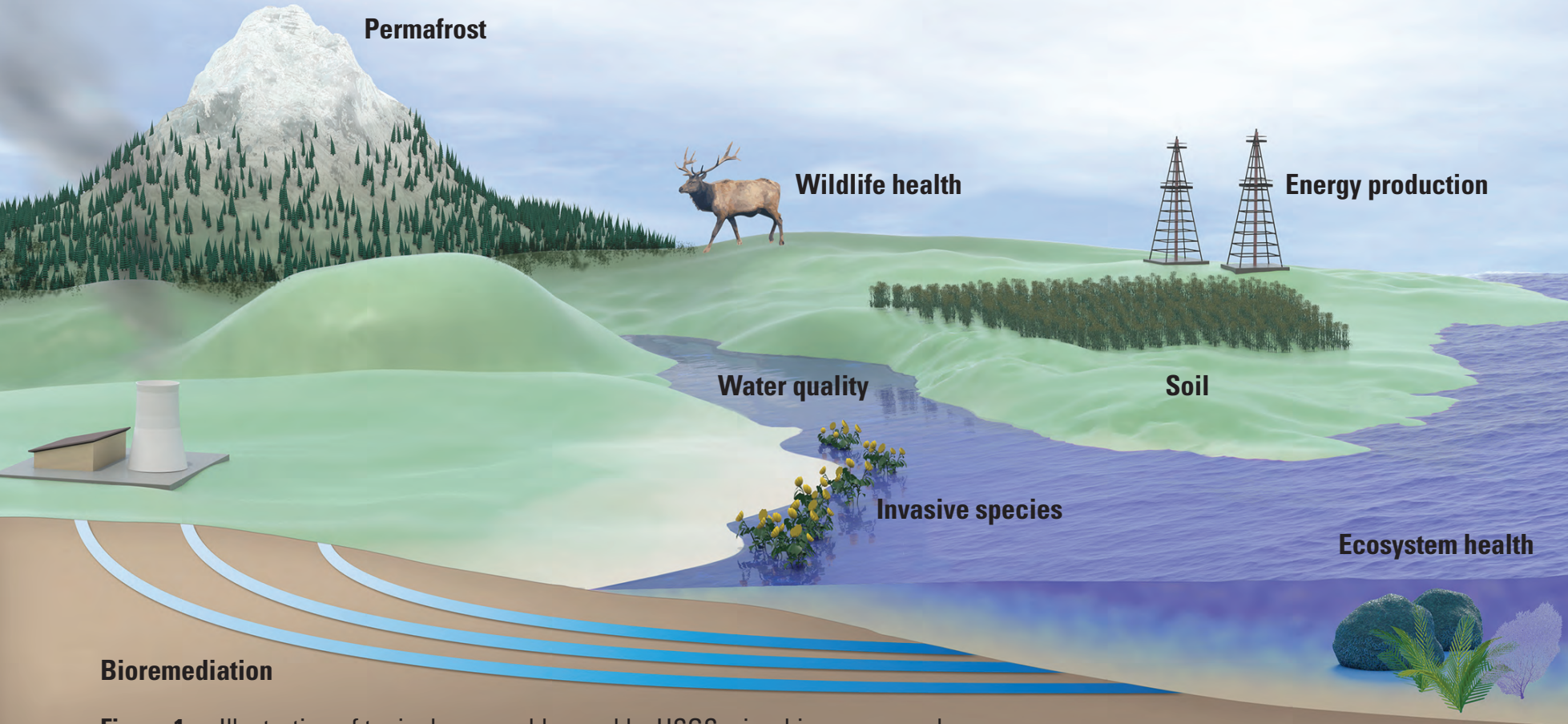

Figure 1. Illustration of topical areas addressed by USGS microbiome research. 


\section{Invasive Species Management}

It is estimated that more than 5,000 invasive plant species have displaced native plants in the United States, negatively affecting ecosystems and the economy. Billions of dollars are spent each year on the control and removal of invasive species; approximately $\$ 100$ million is spent annually on invasive aquatic weeds. Researchers at the USGS Great Lakes Science Center are partnering with the Great Lakes Commission and several universities to develop control methods and management strategies targeting the symbiotic relations between invasive plants (for example, Phragmites australis, a reed) and their microbiomes (http://www. greatlakesphragmites.net/research/control).

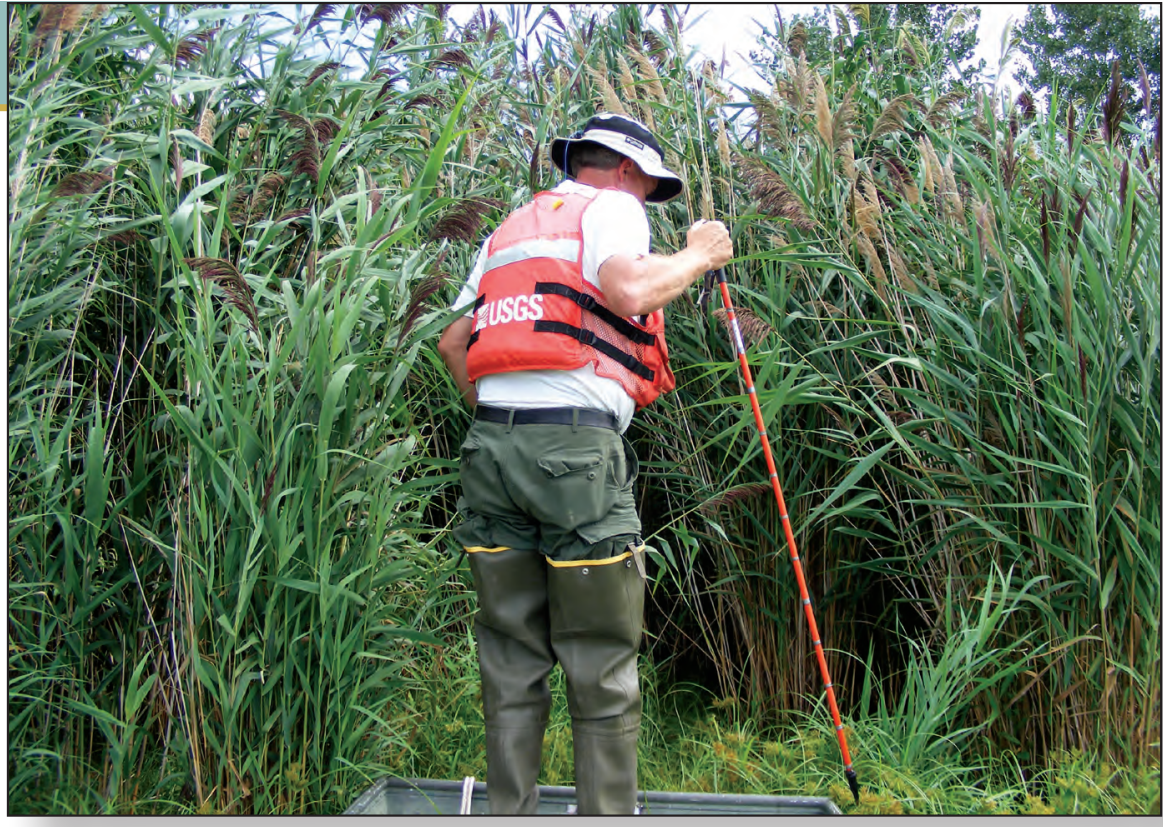

Photograph by Kurt Kowalski, U.S. Geological Survey

\section{Wildlife Health and Disease}

White-Nose Syndrome (WNS) is a fungal disease that has caused the death of six million hibernating bats across the United States and Canada since it emerged in 2007. Bats save U.S. farmers more than $\$ 3$ billion annually in pest control services because they eat insects that damage crops and carry diseases. Bats also play a role in plant pollination and seed dispersal. The USGS National Wildlife Health Center, with U.S. Fish and Wildlife Service and other partners, continues to play a primary role in WNS surveillance and research. Current projects include the collection of baseline skin microbiome data on bats to identify natural defenses and potential biocontrol agents against WNS (https://www.nwhc.usgs.gov/disease information/white-nose_syndrome/).

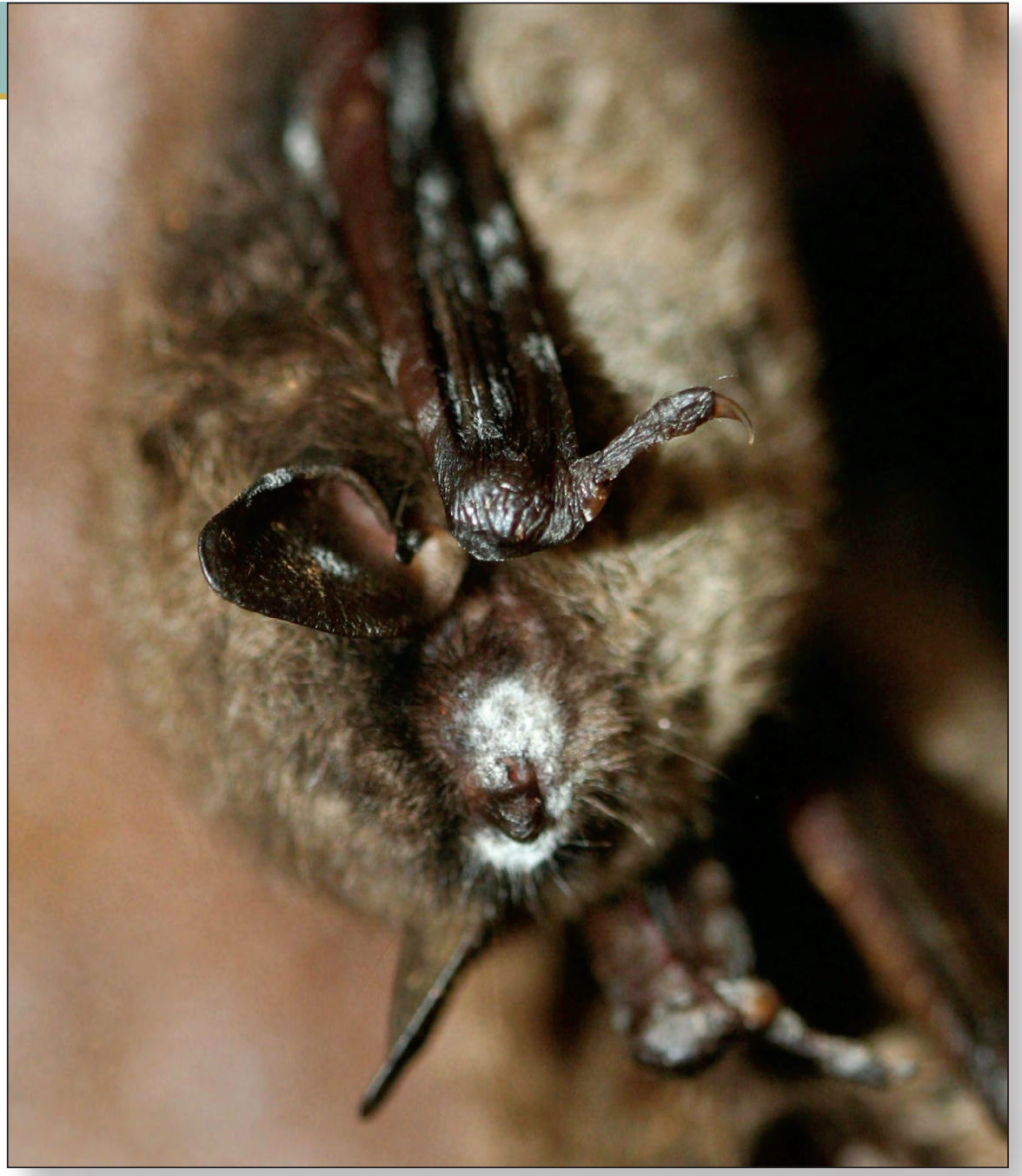

Photograph by Greg Turner, Pennsylvania Game Commission 


\section{Spread of Antibiotic Resistance}

Drug-resistant bacteria are estimated to cause at least 2 million illnesses and more than 20,000 deaths annually in the United States. USGS Alaska Science Center researchers working with academic colleagues in Sweden found that gulls in urban areas of Alaska were more likely to be carriers of antibiotic resistant strains of the bacteria Escherichia coli (E. coli) than gulls from remote areas. Although E. coli is a normal part of gull gut microbiomes, the detection of multi-drug resistant strains in wild birds suggests transmission from human waste, such as landfills or wastewater, and raises questions about the risk for re-transmission in areas where people and gulls interact (https://www.usgs.gov/news/gulls-alaska-

found-carry-antibiotic-resistant-e-coli).

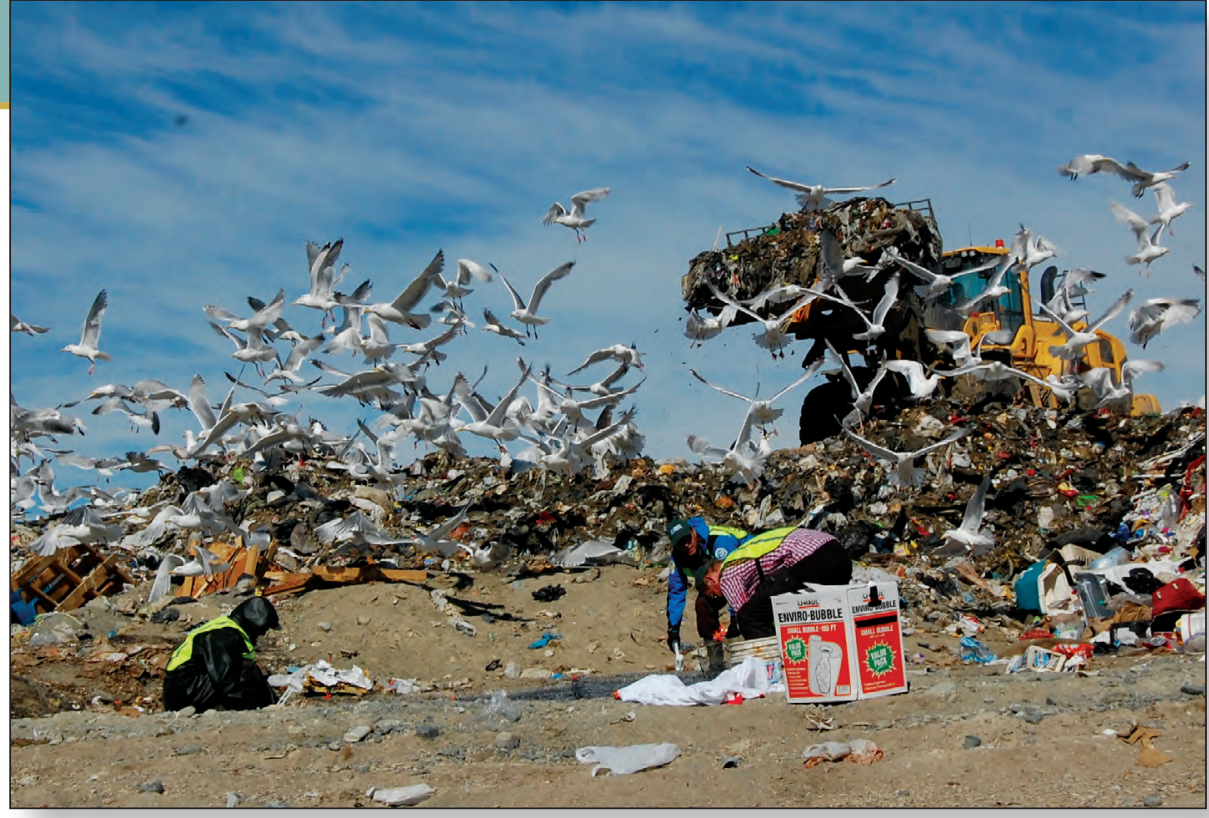

\section{Ecosystem Conservation and Management}

Hundreds to thousands of feet deep in the ocean, more than 3,000 species of deep-sea corals have been identified, and more continue to be discovered. Corals, which can be hundreds of years to centuries old, provide essential habitat for commercial fish species and harbor novel biodiversity. Researchers at the USGS St. Petersburg Coastal and Marine Science Center are identifying baseline microbiomes of deep-sea coral species for conservation and management of these natural resources. Baselines are critical for impact assessment and restoration because coral habitats are particularly sensitive to climate change and human activities, such as energy exploration, fishing, and mining, that are moving into greater ocean depths (https://coastal.er.usgs.gov/ coral-microbes/discovre/).

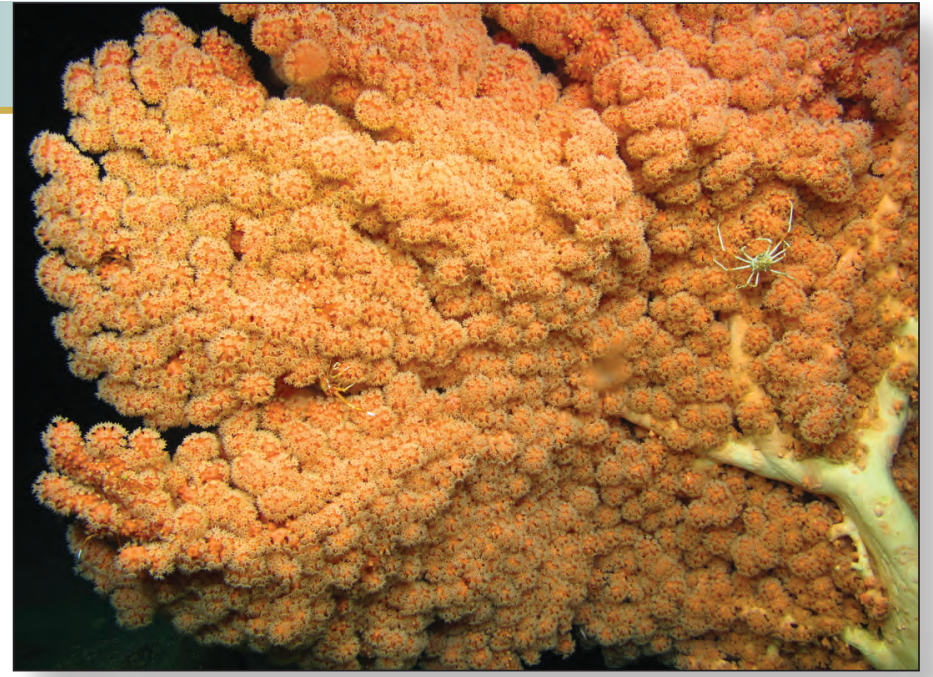

Photograph courtesy of Deepwater Canyons 2012-Pathways to the Abyss, Bureau of Ocean Energy Management/National Oceanic and Atmospheric Administration Office of Ocean Exploration and Research/U.S. Geological Survey

\section{Improving Production of Natural Gas}

Production of natural gas associated with coal beds accounts for approximately 7 percent of the total natural gas produced annually in the United States. Natural gas is a relatively clean source of energy. Coal-bed gas is composed mainly of methane, some of which is generated by microbial processes. USGS scientists are working to enhance production of this natural gas through stimulation of the coal-bed microbiome. Their work could lead to technologies that couple biological systems like photosynthesis and methane production for the generation of natural gas and algal biofuels while sequestering carbon dioxide (https://energy.usgs. gov/OilGas/UnconventionalOilGas/CoalbedGas.aspx).

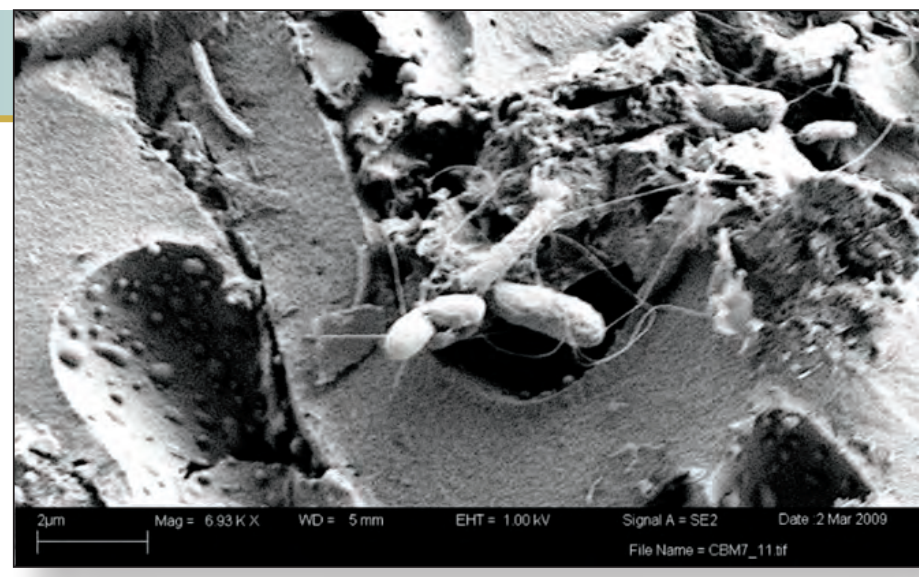

Photograph by Elliott Barnhart, U.S. Geological Survey 


\section{Permafrost}

Frozen soils offer unique environments in which to study the soil microbiome. Not only is permafrost important to the global carbon cycle because it stores vast quantities of carbon that are vulnerable to warming and thaw, but it is important as an environment in which to study exobiology. Exobiology is the study of possible life on other planets. The microbiome of permafrost can be examined to discover the mechanisms by which microorganisms survive in frozen conditions over geologic time. Researchers at the USGS Menlo Park campus are collaborating with the U.S. Department of Energy (Lawrence Livermore National Laboratory), NASA, and academic partners to study the permafrost microbiome using cutting-edge technologies. Data acquired will improve predictions of carbon cycling processes and the possibility of life on other planets (https://carbon.wr.usgs.gov/).

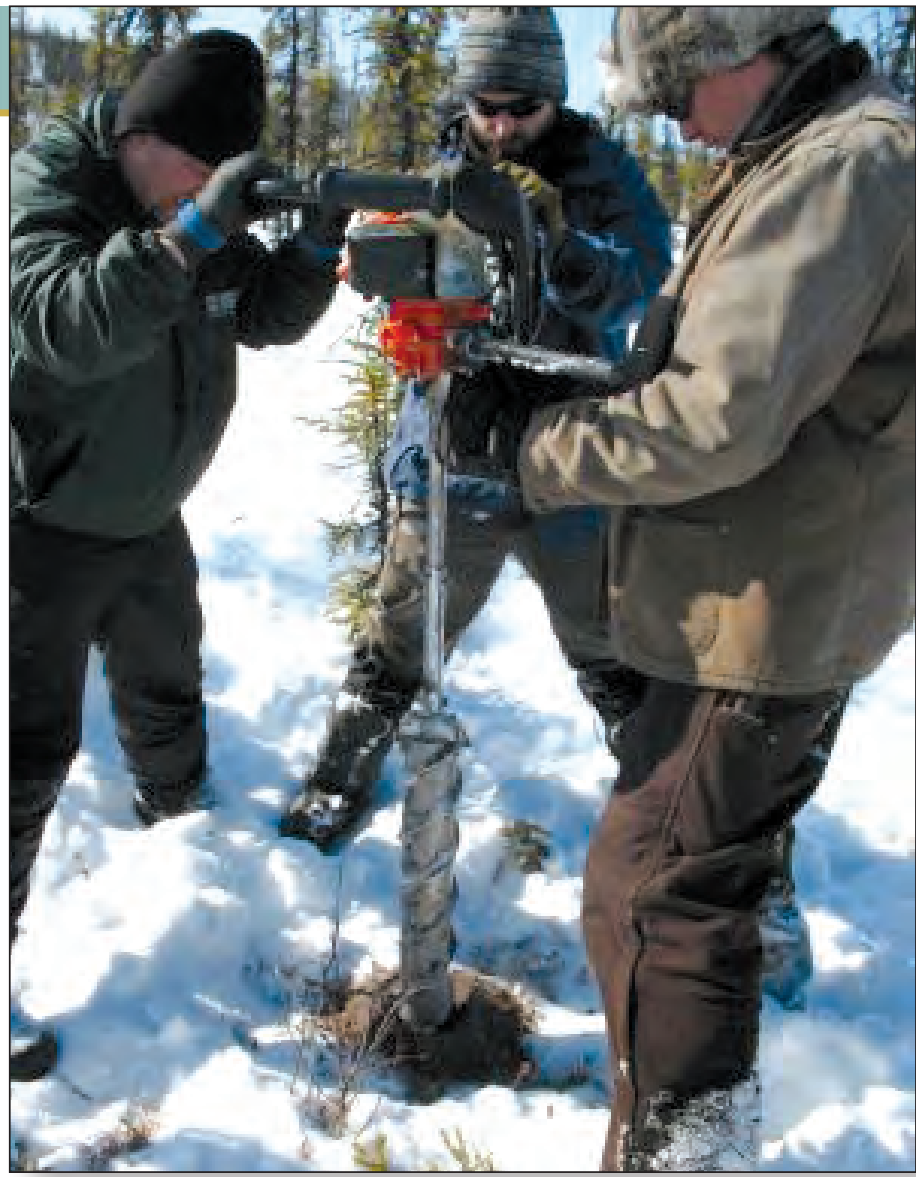

Photograph by Mark P. Waldrop, U.S. Geological Survey

\section{Bioremediation}

Energy production, military, and industrial activities have resulted in extensive contamination of water, sediments, and soils with compounds such as chlorinated solvents, hydrocarbons, heavy metals, and radionuclides. These contaminants can impair ecosystems, affecting the health of plants, animals, and people. Fortunately, the vast diversity of microbes includes organisms with the ability to degrade or clean up many of these harmful contaminants. Here, a scientist cultures bacteria from a contaminated site. Researchers at the USGS Reston Microbiology Laboratory are studying environmental microbiomes capable of naturally breaking down or removing contaminants that resulted from various human activities, including oil and gas extraction and industry (https://water.usgs.gov/nrp/microbiology/).

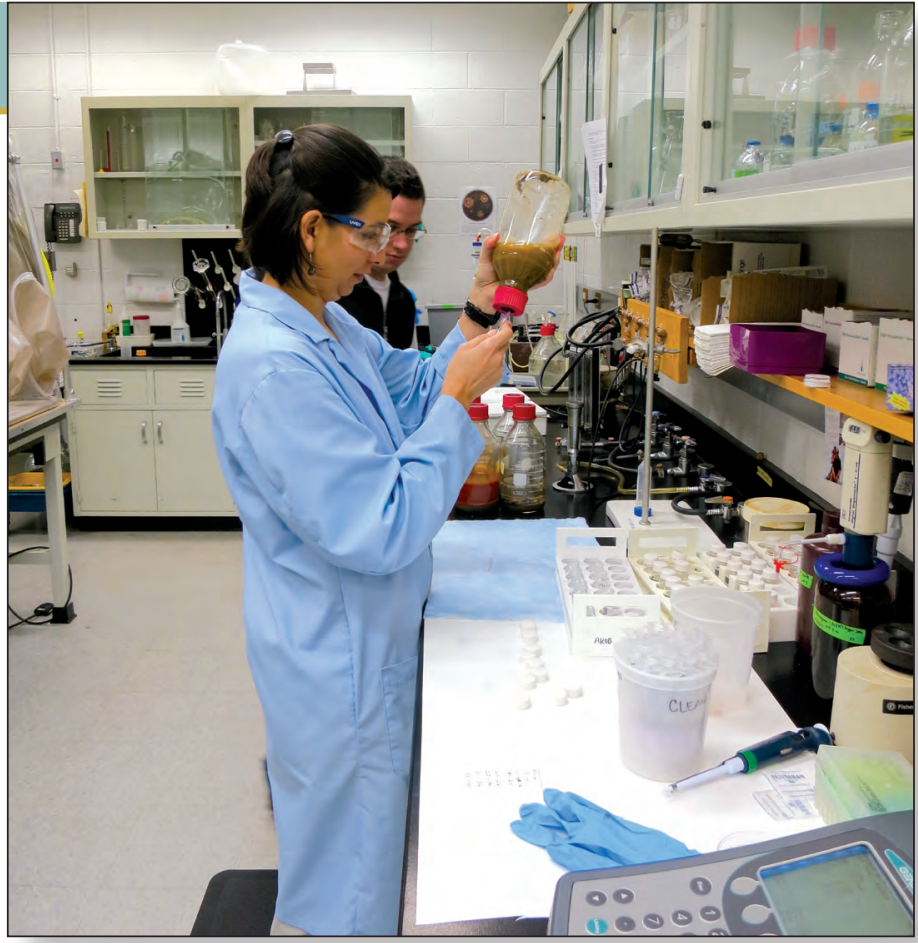

Photograph by Andrea Fraser, U.S. Geological Survey 